\section{Inflammation in SLE-PAH: good news or not?}

We read with great interest the recent study of Sun et al on the two distinct clinical phenotypes of systemic lupus erythematosus (SLE)-associated pulmonary arterial hypertension (PAH). ${ }^{1}$ Based on the baseline characteristics of SLE-PAH, two clusters of patients were identified as vasculitic subtype, which had systemic manifestations and high SLE disease activity, and vasculopathic subtype, which tended to have low disease activity but pure PAH. It showed that the survival of patients with vasculitic subtype was worse than those with vasculopathic subtype. The time interval between the diagnosis of SLE and PAH ( $<2$ years) and Systemic Lupus Erythematosus Disease Activity Index (SLEDAI >9) were identified as two independent predictors of vasculitic subtype. A weighted score $\geq 2$ combining these two factors (time interval $<2$ years and $\geq 2$ years were 1 and 0 point, SLEDAI $>9,5-9$ and $<5$ were 2, 1, 0 point) was further developed as prediction model of vasculitic subtype.

Peking Union Medical College Hospital established a prospective cohort of patients with SLE-PAH in China since 2009. A total of 145 patients with SLE-PAH were enrolled. All patients were evaluated by right heart catheterisation to confirm the diagnosis of PAH. The mean pulmonary arterial pressure was $46.4 \pm 10.9 \mathrm{~mm} \mathrm{Hg}$, the pulmonary vascular resistance was $10.0 \pm 4.2 \mathrm{WU}$ and cardiac index was $2.8 \pm 0.8 \mathrm{~L} / \mathrm{min} \times \mathrm{m}^{2}$. Other groups of pulmonary hypertension were excluded by chest highresolution CT scan, pulmonary function test and ventilation/ perfusion (V/Q) scan.

According to the weight score combining the time interval between the diagnosis of SLE and PAH and SLEDAI, patients were divided into vasculitic subtype (weight score $\geq 2,34$ cases) and vasculopathic subtype (weight score $<2,111$ cases). Kaplan-Meier analysis showed that the survival of vasculitic subtype tended to be better than vasculopathic subtype with the 3 -year survival rates of $92.4 \%$ versus $85.5 \%(p=0.52$, HR $0.70,95 \%$ CI 0.24 to 2.05 ; figure $1 \mathrm{~A}$ ). The conclusion was not changed after adjusting treatment variation (data not shown). Besides mortality, we set a secondary end point as treatment goal achievement (TGA). Treatment goal was defined as achieved when all of the following four aspects were reached, including (1) clinical symptoms: no signs of right heart failure, syncope or progression; (2) WHO functional class (FC) I or II, or six-minute walking distance (6MWD) $>380-440 \mathrm{~m}$; (3) serology: brain natriuretic peptide (BNP) $<50 \mathrm{ng} / \mathrm{L}$ or $\mathrm{N}$ terminal-pro brain natriuretic peptide (NT-proBNP) $<300 \mathrm{ng} / \mathrm{L}$; and (4) cardiac imaging: normal right atrial area according to echocardiography. Notably, it showed that the vasculitic subtype tended to reach
TGA earlier than vasculopathic subtype with the 3 -year TGA rates of $71.2 \%$ versus $60.7 \%(\mathrm{p}=0.31$, HR $1.34,95 \%$ CI 0.76 to 2.31 ; figure $1 \mathrm{~B}$ ).

According to the literature, the non-inflammatory subtype and the inflammatory subtype of SLE-PAH was previously being inferred. ${ }^{2}$ Our study also showed that baseline inflammation such as serositis was an independent predictor of TGA, which associated with long-term survival (unpublished data). Patients with serositis at baseline tended to benefit from intensive immunosuppressive therapy and have a better clinical outcome (unpublished data), which indicates that inflammation may play a significant role in the prognosis and treatment response in SLE-PAH. It is indeed necessary to distinguish patients with SLE-PAH into the two phenotypes-vasculitic or vasculopathic subtypes. However, the prognosis of vasculitic subtype may not be worse than vasculopathic subtype and needs to be further studied. Several studies showed improvement from immunosuppressant therapy. ${ }^{3}{ }^{4}$ It has been reported that patients with a simultaneous diagnosis of PAH and CTD (the diagnosis of PAH and CTD within 6 months) and treated with immunosuppressant therapy were prone to be short-term responders and had the best survival. ${ }^{5}$ Our data showed that the patients with vasculitic subtype tend to get TGA easier and had a higher 3-year survival rate (even without clinical significance), suggesting that the vasculitic subtype has a stronger inflammatory background and may have a better treatment response in immunosuppressant therapy. Notably, the timing of treatment can also affect the prognosis that patients may benefit from early immunosuppressant treatment. Further study is on call to answer these questions.

\section{Junyan Qian, ${ }^{1}$ Mengtao Li, ${ }^{1}$ Jiuliang Zhao, ${ }^{1}$ Qian Wang, ${ }^{1}$ Zhuang Tian, ${ }^{2}$ Xiaofeng Zeng ${ }^{1}$}

${ }^{1}$ Department of Rheumatology, Key Laboratory of Rheumatology and Clinical Immunology, Ministry of Education, Peking Union Medical College Hospital, Peking Union Medical College and Chinese Academy of Medical Science, Beijing, China ${ }^{2}$ Department of Cardiology, Peking Union Medical College Hospital, Peking Union Medical College and Chinese Academy of Medical Science, Beijing, China

Correspondence to Dr Mengtao Li and Dr Xiaofeng Zeng, Department of Rheumatology, Peking Union Medical College Hospital, Beijing, China; mengtao.li@cstar.org.cn, xiaofeng.zeng@cstar.org.cn

Contributors Conception and design: JQ, ML, XZ. Analysis and interpretation: JQ, QW, JZ, ZT. Drafting the manuscript for important intellectual content: JQ, ML, XZ.

Funding The study was supported by the Chinese National Key Technology R\&D Program, Ministry of Science and Technology (2017YFC0907601, 2017YFC0907602, 2017YFC0907603), and the Chinese National High Technology Research and Development Program, Ministry of Science and Technology (2012AA02A513).

Competing interests None declared.

Patient consent Obtained.

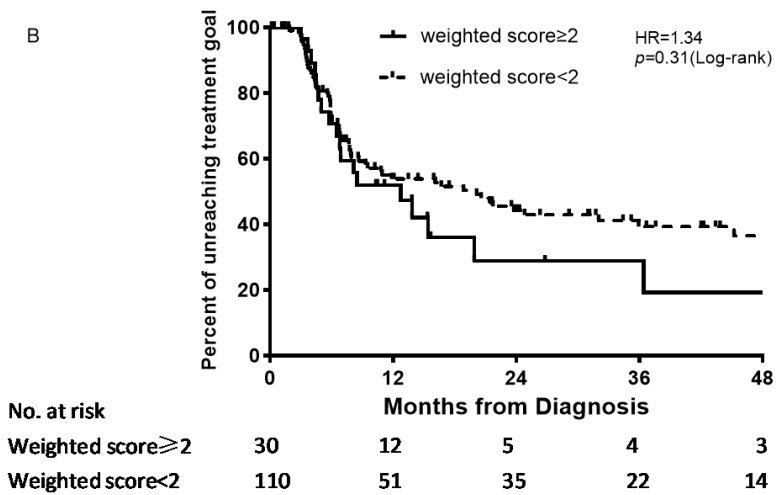

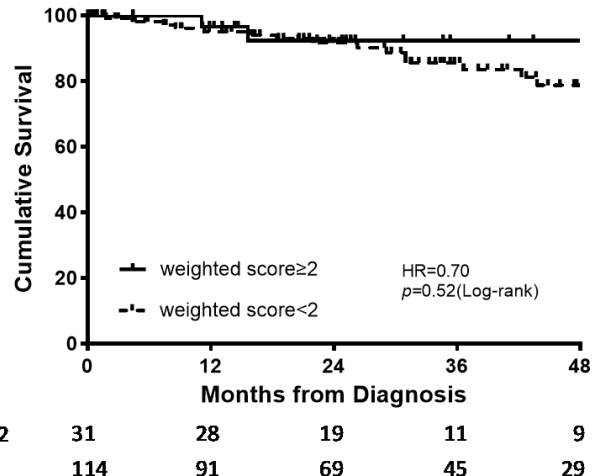


Provenance and peer review Not commissioned; internally peer reviewed.

(C) Author(s) (or their employer(s)) 2019. No commercial re-use. See rights and permissions. Published by BMJ.

\section{(A) Check for updates}

To cite Qian J, Li M, Zhao J, et al. Ann Rheum Dis 2019:78:e135.

Received 17 October 2018

Accepted 26 October 2018

Published Online First 14 November 2018

\section{S Linked}

http://dx.doi.org/10.1136/annrheumdis-2018-214647
Ann Rheum Dis 2019;78:e135. doi:10.1136/annrheumdis-2018-214605

\section{REFERENCES}

1 Sun F, Lei Y, Wu W, et al. Two distinct clinical phenotypes of pulmonary arterial hypertension secondary to systemic lupus erythematosus. Ann Rheum Dis 2019;78:148-50.

2. Chow SL, Chandran V, Fazelzad R, et al. Prognostic factors for survival in systemic lupus erythematosus associated pulmonary hypertension. Lupus 2012;21:353-64.

3. Jais X, Launay D, Yaici A, et al. Immunosuppressive therapy in lupus- and mixed connective tissue disease-associated pulmonary arterial hypertension: a retrospective analysis of twenty-three cases. Arthritis Rheum 2008:58:521-31.

4. Huang C, Zhang S, Tian Z, et al. Could pulmonary arterial hypertension be an active index of systemic lupus erythematosus? A successful case of SLE-PAH cured by methylprednisolone pulse therapy. Lupus 2014;23:1533-6.

5. Yasuoka H, Shirai Y, Tamura Y, et al. Predictors of favorable responses to immunosuppressive treatment in pulmonary arterial hypertension associated with connective tissue disease. Circ J 2018:82:546-54. 